UDC 811.161.1:811.131.1’367.625

Submitted: 05.08.2016

LBC 81.002

Accepted: 12.09 .2016

\title{
IMPERATIVE VERBAL FORMS AS PRAGMATIC MARKERS (ON THE MATERIAL OF RUSSIAN AND ITALIAN LANGUAGES)
}

\author{
Natalya K. Guseva \\ G. D’Annunzio University, Pescara, Italy
}

\begin{abstract}
The article is devoted to the analysis of the usage of the imperative forms of some cognitive and volition verbs as well as basic verbs of the politeness category in the dialogic discourse of Russian and Italian languages. In the oral speech the imperative verbal forms function as structurizing elements that organise the dialogic interaction. The imperative verbal forms mark different actions of speech and non-speech character. A regular usage of the imperative forms out of the phrase propositional content allows the dialogue participant to codify and interpret adequately the propositional part of the sentence. The author carries out a functional-pragmatic analysis of speech acts with imperative verbal forms, the main function of which is to structure the dialogic units and the dialog as a whole comprising their illocutionary force. The study of the material of more than one language has enabled to determine that in pragmaticalization of the imperative forms the total desemantization does not occur and the capability of the imperative forms to serve as pragmatic markers is determined by their lexical meaning, combinatory property and possibility to form the imperative. The choice of one or another pragmatic marker is determined by linguistic, paralinguistic or extralinguistic factors. The function of the imperative verbal forms of some lexical-semantic group is close to that of the performatives. dialogue.

Key words: dialogic speech, pragmatics, pragmatic marker, imperative, function, illocutionary structure of

\section{ИМПЕРАТИВНЫЕ ГЛАГОЛЬНЫЕ ФОРМЫ КАК ПРАГМАТИЧЕСКИЕ МАРКЕРЫ (НА МАТЕРИАЛЕ РУССКОГО И ИТАЛЬЯНСКОГО ЯЗЫКОВ)}

\author{
Наталья Константиновна Гусева \\ Университет им. Габриэля Д’Аннунцио, г. Пескара, Италия
}

\begin{abstract}
Аннотация. В статье анализируется узус императивных форм некоторых глаголов когнитивной и волеизъявительной семантических сфер, а также основных глаголов категории вежливости в пространстве русского и итальянского диалогического дискурса. В результате сопоставительного функционально-прагматического изучения речевых актов, которые содержат императивные глагольные формы, подтверждены положения о том, что в устной речи императивные глагольные формы кроме основных интеракциональных функций выполняют структурирующую функцию, организуя диалогическое взаимодействие и маркируя различные действия как речевого, так и неречевого характера; что регулярное употребление императивных форм, выведенных за пределы пропозиционального содержания высказывания, позволяет участникам диалога адекватно кодифицировать и интерпретировать пропозициональную часть высказывания. Автором статьи установлено, что в разных языках в процессе прагматикализации императивных форм не происходит полной десемантизации глаголов и способность глагольного слова быть прагматическим маркером обусловлена его лексическим значением, сочетаемостными каче-

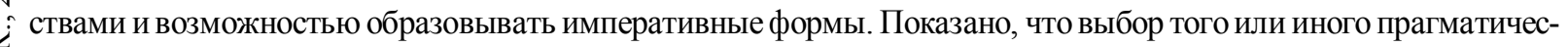
кого маркера определяется лингвистическими, паралингвистическими и экстралингвистическими факторами, а некоторые императивные глагольные словоформы по своим функциям сближаются с перформативами.

Ключевые слова: диалогическая речь, прагматика, прагматический маркер, императив, функция, иллокутивная структура диалога.
\end{abstract}


1

Императив выступает в качестве языкового средства реализации определенных функций языка (апеллятивной, регулятивной, волюнтативной и конативной) и связан с различными типами высказываний побудительной семантики: категоричным или настойчивым требованием, приказом, советом, просьбой, приглашением, разрешением, запретом. Употребляя в речи императив, «говорящий, самим фактом своего высказывания, пытается каузировать совершение некоторого действия (эксплицитно указанного в этом высказывании)» [4, с. 21]. Тем не менее в речевой практике встречаются высказывания (речевые акты), содержащие императивные формы глаголов ${ }^{1}$, не являющиеся необходимыми для каузации, с целью которой говорящий производит данное речевое действие. Эти императивные формы выполняют структурирующую (организующую) функцию при выстраивании диалога коммуникантами. Например:

(1) Извините, пожалуйста, вы не подскажете, где здесь остановка автобуса?

(2) Скажите, пожалуйста, который час?

(3) Разрешите представиться: Иван Иванов.

(4) Слушай, давай не пойдем сегодня в кино.

Выделенные императивные формы можно опустить, не нарушая при этом целостности пропозиционального содержания следующих за ним высказываний. Вполне приемлемы в диалоге высказывания Kоторый час? Давай не пойдем сегодня в кино без вводных скажите или слушай. Однако с прагматической точки зрения употребление названных форм необходимо, поскольку оно облегчает достижение необходимого перлокутивного эффекта.

В лингвистике эти и подобные им регулярные формы чаще всего относят к формулам вежливости (см.: [8; 14]), хотя в структуре диалога они наряду с другими языковыми средствами играют роль опорных элементов, некоего каркаса для высказываний определенного пропозиционального содержания.

Развитие диалога часто происходит спонтанно, и диалогическая речь - это, как правило, речь неподготовленная. Для ее успешного построения коммуниканты устанавливают некоторые ориентиры - маркированные языковые средства. С их помощью говорящий «указывает» слушающему на то, что еще не произнесено, но уже существует в виде внутреннего мотива высказывания. Говорящий делает акцент на той информации, которая окажется значимой для правильной интерпретации, подготавливает слушающего к восприятию какого-либо сообщения.

Языковые средства, позволяющие структурировать диалог по определенным схемам, в англоязычной научной литературе названы discourse markers [18; 22], pragmatic markers [16; 19], discourse particle [12], pragmatic particles [21]; в италоязычной - segnali discorsivi [13] и в русскоязычной - дискурсивные маркеры [3]. Различия в терминологии объясняются тем, что лингвисты проводят классификацию анализируемых языковых средств на разных основаниях.

Мы рассматриваем диалог как вид речевой деятельности по осуществлению двумя и более коммуникантами совместного решения определенных задач посредством клишированных речевых действий (высказываний), которые включают императивные глагольные формы, выполняющие в качестве основных функции установления контакта между коммуникантами и структурирования диалогических единств (ДЕ) и диалога в целом. Для обозначения этих клише мы, вслед за У. Ленк (U. Lenk), используем термин «прагматические маркеры» (pragmatic markers) на том основании, что их прагматическая функция выражена гораздо ярче дискурсивно-маркировочной (фреймовой) функции: «While pragmatic particles in general are often associated with different functions in discourse, such as politeness issues, indicating the speaker's stance towards her / his own utterance, and many others, the subgroup of discourse markers is mainly involved with indicating various features of discourse structure. Studies that investigate pragmatic markers often focus more on the interactional aspects between the participants that are expressed through the use of particles. One of the most prominent functions of discourse markers, however, is to signal the kinds of relations a speaker perceives between different part of the discourse» [19]. 
Императивные формы глаголов в примеpax (1)-(4) не десемантизируются полностью и по своей функции относятся не к дискурсивным, а к прагматическим маркерам: «...the meaning of the expression, when used as a pragmatic marker, is the same as when it is used as a propositional formative and it is only its function which differs» $[16$, p. 171]. Они свидетельствуют об иллокутивной силе последующего высказывания и являются сигналом перехода к новому речевому действию.

Рассмотрим высказывания на русском и итальянском языках, содержащие императивные формы: функции этих форм в диалогических единствах в аспекте дискурсивной интерпретации, тип иллокутивной зависимости в аспекте внутрифразовой интерпретации ${ }^{2}$ и сочетаемостные свойства.

\section{2}

Для привлечения внимания незнакомого собеседника часто употребляются глаголы в повелительном наклонении, выражающие категорию вежливости: в русском языке это глаголы извинить и простить, а в итальянском perdonare и scusare. Они используются при обращении к любому человеку, и за императивом обычно следует вопрос или просьба:

(5) Извините, где здесь стоянка такси?

(6) Простите, передайте мне, пожалуйста, соль.

(7) Mi perdoni, dov'è la fermata di taxi?

(8) Mi scusi, mi passi il sale, per favore.

Императивные формы глаголов в предложениях (5)-(8) участвуют в оформлении направленности речи, но не обозначают при этом конкретного собеседника. Понимание, кому именно адресовано высказывание, достигается в результате анализа экстралингвистической ситуации. Такой способ привлечения внимания эффективен потому, что у говорящего не возникает необходимости распознавать социальный статус человека, к которому он обращается [7, с. 117]. Универсальность обращения в форме императива и некоторые социально-исторические особенности развития российского общества привели к тому, что эта форма в современном русском языке стала более частотной по сравнению с номинативными обращениями типа госпожа, господин, девушка, мужчина и т. д. В итальянском языке, напротив, такие номинативные обращения, как signore / -ra, signorina, а также титулы-вокативы dottore, avvocato, architetto распространены широко, но наряду с ними используются упомянутые выше императивные формы, например:

(9) Signora, mi scusi, dov'è la fermata di taxi?

Императивные формы извините, проcmume, perdoni, scusi в (5)-(8) выполняют вокативную и фатическую функции, сохраняя семантику просьбы о прощении за возможное беспокойство, причиняемое обращением с вопросом, и могут быть определены как перформативы [6, с. 88]. Перформатив-извинение придает всему высказыванию оттенок вежливости, что наблюдается в сопоставляемых языках. В русском языке такие императивы употребляются с дополнительным маркером вежливости пожалуйста, а в итальянском без него, например:

(10) Извините, пожалуйста, который час?

(11) Mi scusi, che ore sono?

Для привлечения внимания в русском языке также используются этикетные фразы с глаголом быть в повелительном наклонении: будьте добры и будьте любезны:

(12) Будьте любезны, скажите, пожалуйста, какой автобус идет в центр?

(13) Будьте добры, передайте на билет, пожалуйста!

Двойной императив (прагматический маркер в форме императива + фактитивный императив) сообщает всему высказыванию повышенную вежливость. Подобные высказывания являются социально маркированными. Как видно из (12) и (13), фразы привлечения внимания с глаголом быть в повелительном наклонении сочетаются со знаменательным каузативным глаголом в форме императива. Эти же формы в сочетании с инфинитивом знаменательного глагола утрачивают функцию прагматического маркера и служат выражению волеизъявления:

(14) Будьте любезны передать на билет. 
Высказывание с инфинитивом (при одинаковом плане содержания) приобретает бо́льшую категоричность и утрачивает характеристику повышенной вежливости, свойственную высказываниям с двойным императивом.

Подобное явление наблюдается и в итальянском языке в высказываниях, содержащих императив глаголов fare / essere и каузативный глагол в инфинитиве:

(15) Mi faccia il piacere di rispondere.

(16) Mi faccia la cortesia di spiegare il motivo del suo comportamento.

(17) Sia così gentile da riferire al direttore la mia richiesta.

В таком виде, в каком они даны в примерах, императивные формы не имеют характеристик прагматических маркеров и расположены в порядке уменьшения категоричности: (15) отличается некоторым оттенком раздражения и нетерпения, а в (17) его не наблюдается.

Прагматикализации императивной глагольной формы (см.: [15]) может служить ее позиция в структуре диалога и отношения с последующей пропозицией. Речевой акт (далее - РА) с фатической формулой совмещает в себе иллокутивное вынуждение и самовынуждение [2]. Так, высказывание, обращенное к незнакомому собеседнику,

(18) Простите, как проехать к железнодорожному вокзалу?

(19) Scusi, come posso arrivare alla stazione?

состоит из двух РА, причем первый реализован императивной формой глагола простить / scusare и связан со вторым отношением самовынуждения. Фатический императив, привлекая внимание слушающего, одновременно вынуждает говорящего продолжать реплику. Однако даже если извините / (mi) scusi произносится отдельно от самого вопроса или просьбы и говорящий как бы ждет от слушающего подтверждения того, что коммуникативный канал активирован, то иллокутивно вынуждаемая реакция слушающего будет невербальной (взгляд в сторону говорящего) или вербальной (приглашение к дальнейшему речевому действию, например, да, слушаю вac в русском языке или si, mi dica в итальянском). Иными словами, фатический импера- тив является сигналом (маркером) незаконченности высказывания. Иллокутивной целью в (18) и (19) является не просто установление контакта, а получение конкретной информации. Перлокутивный эффект обеспечивается не первым (nростите / scusi), а вторым РА в составе (18) и (19): как проехать к железнодорожному вокзалу? / come posso arrivare alla stazione?

\section{3}

Для привлечения внимания русскоговорящие и италоговорящие коммуниканты могут использовать императивные формы глаголов восприятия и мысли. К самым употребительным глаголам этой ЛСГ прежде всего относятся: слушать / сльшиать, видеть / смотреть, думать, представлять и их видовые пары в русском языке и ascoltare / sentire, vedere / guardare, pensare, immaginare в итальянском.

Перечисленные лексемы не являются полными субститутами глаголов, рассмотренных ранее, в силу различий в семантике. Вследствие этого извините, простите, (mi) scusi, mi perdoni используются для привлечения внимания к говорящему в системе координат «я-здесь-сейчас-обращаюсь к тебе», а императивные формы глаголов восприятия и мысли привлекают внимание к высказыванию в системе координат «я-здесь-сейчас-говорю следующее». Они выступают в роли активизаторов модального смысла в разговорной речи (см.: [11]). Область их применения в обоих языках ограничивается диалогическим взаимодействием адресанта со знакомым ему коммуникантом, поскольку императивы со значением восприятия и мысли относятся к формам со сниженной вежливостью и чаще всего используются при обращениях на $m b l[8$, с. 11-12], хотя могут быть использованы и при обращении на $8 b l$, но с несколько иной функцией: со стороны слушающего для прерывания речи говорящего, то есть для смены очередности или перемены темы диалога.

Глаголы зрительного и слухового восприятия в обоих языках делятся на глаголы, называющие волевое восприятие (смотреть / guardare, слушать / ascoltare) и неволевое восприятие (видеть / vedere, сльшать / 
sentire). Глаголы волевого восприятия (итал. «verbi volontari») обозначают действие, которое агенс осуществляет с бо́льшей степенью контроля, чем в действиях, обозначаемых глаголами неволевого восприятия (итал. «verbi involontari»). Чтобы осуществить действия, выражаемые глаголами смотреть, слушать, guardare, ascoltare, агенсу необходимо приложить определенное волевое усилие: направить взгляд на какой-то предмет, отыскать его глазами, рассматривать его с целью ознакомления либо направить слух на что-нибудь, исследовать на слух, то есть эти действия предполагают активную когнитивную деятельность с последующим анализом и синтезом полученной информации. Глаголы неволевого восприятия «обозначают некоторое состояние сознания, направленное на объект» [1, с. 20]. В современном русском языке существуют ограничения на образование и употребление императивных форм глаголов видеть и слышать: в соответствии с нормами литературного языка они не образуют императивных форм. В итальянском языке не наблюдается ограничений на употребление глаголов неволевого восприятия в императивной форме: глаголы vedere и sentire образуют императивные формы и широко употребляются в речи, в том числе в роли прагматических маркеров.

Для глаголов зрительного и слухового восприятия общим является не только референциальное значение, связанное с одним или несколькими органами чувств, но и значение, заключающее в себе общее понятие когнитивной деятельности человека. Например, глагол видеть и его эквиваленты во многих индоевропейских языках приобрели когнитивные смыслы и объединили в себе значение как перцептивной, так и ментальной сферы $[1$, с. 8], а итальянский глагол sentire называет не только способность воспринимать на слух, сенсорную чувствительность в общем (sentire freddo, sentire dolore), но и эмоциональные состояния, связанные с интеллектом (sentire affetto, sentire mancanza) [17].

Императивные формы глаголов слухового восприятия употребляются в качестве прагматических маркеров привлечения внимания в предложениях типа:
(20) Слушай, пойдем сегодня в кино.

(21) Senti, vogliamo andare al cinema stasera?

(22) Послушайте, нельзя же все время говорить об одном и том же! cose!

(23) Senta, non si può parlare sempre delle stesse

Коммуникативно-прагматическая функция глаголов восприятия в (20)-(23) заключается в активации слухового коммуникативного канала или в поддержании его активности [20, p. 47], но в (20) и (21) они могут восприниматься и как приглашение поразмыслить над предложением пойти в кино. Следует добавить, что в (20) и (21) глагольные формы могут сочетаться с частицей -ка или с наречием ип ро', придавая всему высказыванию более интимный, дружеский характер. В (22) и (23) послуmaŭme / senta служат для обозначения смены диалогических ролей и произносятся обычно решительным тоном с оттенком нетерпения и некоторой угрозы. Прагматические маркеры привлечения внимания и смены очередности могут сочетаться с вокативами, сообщая всему высказыванию характер побуждения, предписания или порицания. Как справедливо отмечает П. Манили (P. Manili), если вокатив выражен прилагательным со значениями пренебрежения, насмешливой вежливости или словосочетаниями с такой семантикой, то глагольная форма приобретает коннотацию угрозы, иногда даже оскорбительной [20, p. 47].

За глаголом (По)слушай! может следовать вопрос, просьба, в том числе косвенная, предупреждение, обещание, признание, предложение и утверждение (см.: [11]):

(24) Слушай, ты не видел мои часы? - косвенная просьба помочь в поиске часов.

(25) Послушай, давай сегодня все доделаем, а завтра уже будем отдыхать! - предложение.

(26) Слушай, он вчера опять не пришел - утверждение.

(27) Слушай, я раньше трех не приду - предупреждение.

Итальянские словоформы senti / senta / sentite выполняют аналогичные функции (подробно см.: [20, p. 47-50]):

(28) Senti, volevo dirti che oggi tarderò qui con il casino che abbiamo non so a che ora riuscirò a liberarmi ${ }^{3}$ - предупреждение. 
(29) Senti, mio caro, non ti odio, anzi mi sei simpaticissimo, ti sono amicissimo, me ne dispiace tanto... - утверждение.

Cлушай! Oh senti! могут быть охарактеризованы как абсолютно зависимый PA, который, будучи произнесенным соответствующим тоном, передает решительность говорящего прекратить нежелательный разговор. Тон высказывания дает понять адресату, что говорящий мог бы еще что-то сказать, но не желает этого делать и предпочитает прекратить разговор.

Из итальянских глаголов восприятия ascoltare реже остальных употребляется как прагматический маркер [17]. Императивные формы ascolta, ascolti преимущественно используются в качестве фактитивного императива, призывающего адресата прислушаться к совету, усиливающего предостережение, замечание-упрек, хотя эти формы и встречаются в роли прагматического фатического маркера, но только в диалектных разновидностях итальянского языка.

Функции глаголов зрительного восприятия видеть / смотреть и vedere / guardare в их императивных формах схожи с функциями глаголов слышать / слушать и sentire / ascoltare. Так, К. Гецци (C. Ghezzi) утверждает, что в итальянском языке глаголы зрительного восприятия в роли прагматических маркеров употребляются чаще для привлечения внимания к объективной информации, в то время как пропозициональное содержание предложений с прагматическими маркерами в императивной форме глаголов слухового восприятия носит субъективный, эмоциональный и оценочный характер [17].

В русском языке в качестве прагматического маркера привлечения внимания к последующему высказыванию или действию встречается императив глагола смотреть:

(30) Смотри, что я придумал.

(31) Смотри: если мы пойдем сегодня в кино, то не успеем подготовиться к завтрашнему семинару.

В (30) и (31) говорящий привлекает не только и не столько зрительное внимание слушающего, сколько предлагает оценить чтолибо, выразить свою точку зрения.

В высказываниях на итальянском языке в роли прагматических маркеров встре- чаются оба глагола зрительного восприятия. Императивные формы vedi, vede в значении «заметь(те)» употребляются в начале фразы и относятся не к сфере «реального», а к сфере интеллектуально-когнитивного зрения $[20$, p. 34]. Формы индикатива настоящего времени и императива vedere омонимичны и затрудняют анализ высказываний, в состав которых они входят. П. Манили (Р. Manili) отмечает, что императивные формы глаголов отделяются от пропозициональной части высказывания обязательной паузой, обозначенной на письме запятой или многоточием. Приведем примеры:

(32) Vedi, figliolo, sono commosso per la semplicit.

(33) Vedi... quella donna mi ripugna anche fisicamente... non so...

$V e d i$ может быть маркером привлечения внимания к факту, который неприятен говорящему или о котором ему нелегко говорить. По нашему мнению, прагматическим соответствием (32) и (33) в русском языке выступают формулы видищь ли / видите ли с последующей пропозициональной частью.

Императивные формы глаголов смотpems / guardare в роли прагматических маркеров обнаруживают признаки десемантизации, от степени которой зависит их позиция в высказывании: в начале, в конце или в середине. Если семантика сохранена, то словоформы смотри(те) / guarda(te) / guardi привлекают зрительное внимание слушающего, подобно тому как словоформы глаголов слуuamb / sentire привлекают слуховое внимание к той сфере действительности, на которую говорящий хочет непременно обратить внимание слушающего. Они встречаются в позиции иллокутивно независимого РА, состоящего с пропозициональной частью в отношении самовынуждения, и на их иллокутивную независимость не влияет факт законченности или незаконченности предыдущей реплики другого коммуниканта:

(34) Guardate: una coccinella!

(35) Смотрите: божья коровка!

В (34) и (35) императивные формы выполняют референциальную функцию, способ- 
ствуя соотнесению произносимых вслед за ними языковых единиц с объектами действительности.

Guarda в начале фразы может привлекать не только зрительное внимание к физическому объекту, обозначенному в пропозициональной части, но и подобно русским смотри / смотрите в (30) и (31) приглашать обратить внимание, оценить, сформулировать свою точку зрения на излагаемое, даже если оно не поддается зрительному анализу и связано с абстрактными понятиями или ситуацией. За императивной словоформой следует повествовательное предложение:

(36) Guarda: se andiamo stasera al cinema non avremo tempo per prepararci per il seminario di domani.

(37) Guarda che puoi prorogare la validità del documento.

В (37) и подобных ему высказываниях, где пропозициональная изъяснительная часть вводится союзом che, говорящий призывает слушающего поразмыслить над предлагаемой перспективой и прийти к определенным заключениям или сообщает слушающему неизвестный тому факт, который, по мнению говорящего, входит в противоречие с имеющейся у слушающего картиной действительности.

Императивные формы глаголов cмompemь и guardare часто выступают маркерами апрехенсива и превентива:

(38) Смотри, свяжешься с ним - будете под забором жить!

(39) Смотри, будь послушной девочкой!

(40) Guarda che prenderai un raffreddore!

(41) Guarda che se continui così finisce male!

\section{4}

Для привлечения внимания к тому, что будет сказано или уже говорится, используется глагол представить, иногда в сочетании с местоимением себе. Описываемая ситуация неизвестна слушающему, и говорящий желает не только ознакомить его с происшедшим, но и приглашает того выразить свое мнение относительно случившегося. Глагол представить, обозначая умственную деятельность, связан с семантической сферой воображения или внутреннего зрения, а его императивные формы используются в качестве маркера, выражающего призыв обдумать и оценить ситуацию, описываемую в пропозициональной части (см. описание десемантизированного варианта глагола смотреть, данное выше), причем в самом маркере заложена субъективно-модальная оценка ситуации со стороны говорящего. Маркер может находиться в начале высказывания, в его середине или конце либо может быть отдельной синтаксической единицей:

(42) Представьте, какой случай: я вчера одиннадцать тысяч выиграл.

(43) Как он найдет своего властелина? Но, представьте себе, нашел.

(44) - Вот как? - Представьте себе. К тому же я спешу.

К прагматическим маркерам можно отнести только вводные словосочетания и предложения со словоформами глагола представить. Высказывания с фактитивным императивом переходного глагола представить с обязательным прямым дополнением не относятся к категории прагматических маркеров: Представьте себе футбольное поле, на котором с одной стороны играют иесть составов, а с другой - один, и вы поймете, что такое современная политическая жизнь России.

В итальянском языке аналогом маркера, представленного в (42)-(44), являются словоформы глагола figurare, которые также могут находиться в начале высказывания, в его середине или конце:

(45) Si figuri (figurati) che io ero ancora all'oscuro di tutto!

(46) Non riuscivo a prendere sonno, figurati, alle tre ero lì che passeggiavo per la casa.

(47) Sono arrivata con quaranta minuti di anticipo ma non c'era nemmeno un posto libero, figurati!

Высказывание Представь(те) себе! может использоваться в качестве положительного ответа на общий вопрос. Такой ответ выражает субъективно-модальное отношение говорящего, и в нем заложено удивление, почти неверие со стороны самого говорящего, к которым он хочет подвести и слушающего:

(48)- Ты успел заехать к Оле? - Представь себе! 
Итальянские глаголы умственной деятельности figurare и immaginare встречаются в качестве утвердительных или отрицательных ответов высокой степени вежливости:

(49) "Non disturbo?" domandò Lisa avvicinandosi... "Figurati" disse la madre.

(50) "Forse sono venuto troppo presto?" egli disse appendendo il mantello e il cappello all'attaccapanni. "Figurati".

Употребление императивных глагольных форм в иллокутивно зависимых и абсолютно зависимых речевых актах со значением утвердительного или отрицательного ответа встречается достаточно часто в русской и итальянской разговорной речи. Так, для выражения согласия (утвердительного ответа) на предложение какой-либо услуги или выполнения действия используются императивные конструкции с глаголам быmb / essere и cdeлать следующего типа:

(51) - Вам сделать чай, Ольга Петровна? - Да. Будыте так любезны!

(52) - А мы вам не будем мешать разговорами? - вежливо осведомился Ваня Манин. - Сделайте одолжение, не стесняйтесь.

(53) - Le preparo un tè? - Grazie. Sia così gentile.

Высказывания (51)-(53) отличаются повышенной вежливостью и являются социально маркированными.

\section{5}

Для анонсирования какого-либо действия со стороны говорящего в речи употребляются императивные формы глаголов со значением волеизъявления разрешить / позволить (CB) и permettere / consentire. В этом значении они сближаются с перформативами (подробно см.: [9, с. 51]):

(54) Я зайду к вам завтра, а сейчас, разрешите, я провожу вас в вашу комнату.

(55) - Разрешите не согласиться, товарищ полковник, - упрямо и скромно наклонил голову Нейман.

(56) Позвольте ознакомить Вас с результатами нашей работы. decisione.

(57) Mi consenta di spiegarLe il motivo della mia

(58) Permettete di introdurre il teorema X.
Эти выражения характерны для официально-делового стиля, обладают высокой степенью клишированности, обусловленной частотностью употребления, и, как правило, используются при обращении к группе людей.

Семантика императивных форм такова, что всегда предполагает существование слушающего, то есть направлена вовне, поэтому они являются прагматическими маркерами диалогического текста, а не монологической речи (высказывания типа Разрешите представить..., возможные в монологической речи, например, в докладе, предполагают наличие слушающих). Иными словами, эти средства служат для иллокутивного структурирования диалога: обозначения смены очередности в диалогическом взаимодействии (например, в (56) говорящий берет слово для выполнения определенного речевого действия; в (57) маркер mi consenta используется для прерывания собеседника и анонсирования следующего речевого действия).

\section{6}

В силу сохранения императивными глагольными формами лексических значений и приобретения ими новых прагматических функций, по отношению к описанным случаям можно говорить о прагматикализации императивных глагольных форм.

Они используются в речи как прагматические маркеры того или иного действия, а именно:

- привлечения внимания;

- манипулирования вниманием слушающего;

- анонсирования следующего действия;

- смены ролей (говорящий / слушающий);

- согласия / несогласия.

Частотность употребления прагматических маркеров зависит от лексической семантики глагола и сложившегося национальнокультурного узуса.

Прагматические маркеры в императивной форме служат для структурного оформления диалогического текста и отдельных минимальных диалогических единств: они наряду с другими средствами формируют их иллокутивную структуру. 
При использовании императивных словоформ в роли прагматических маркеров основной становится их фатическая функция.

Речевой акт с фатической формулой совмещает в себе иллокутивное вынуждение и самовынуждение. Маркер и вводимое им высказывание находятся в отношениях самовынуждения.

Прагматические маркеры с императивными словоформами регулярно используются для введения определенных речевых актов в зависимости от их семантики и типа реплики (иллокутивно вынуждаемая или иллокутивно вынуждающая).

В высказываниях маркеры могут наслаиваиваться друг на друга, повышая степень его вежливости и сообщая ему прагматическую избыточность. В русском и итальянском языках маркеры имеют разные сочетаемостные свойства.

Выбор того или иного прагматического маркера зависит как от лингвистических, так и от паралингвистических или экстралингвистических факторов: от степени знакомства адресанта с собеседником, от пропозиционального значения основного высказывания, его иллокутивной цели, сочетаемости маркера с другими словами.

Функция прагматического маркера зависит от экстралингвистических факторов (например, от степени знакомства коммуникантов), его действие - от позиции в диалогическом единстве.

Императивные глагольные формы в качестве прагматических маркеров по своим функциям сближаются с перформативами.

\section{ПРИМЕЧАНИЯ}

1 Здесь и далее под императивными формами глаголов подразумеваются те глагольные формы, которые однозначно относятся лингвистами к русской императивной парадигме [10, с. 109]; под императивными формами в итальянском языке подразумеваются формы второго лица единственного и множественного числа, а также форма конъюнктива настоящего времени, используемая в качестве императива при обращении к собеседнику на «Вы» [23, p. 477].

2 «Одна и та же единица может интерпретироваться, с одной стороны, внутри предложения (внутрифразовая интерпретация), а с другой-вы- ражать связи между предложениями (дискурсивная)» [5, с. 61$]$.

${ }^{3}$ Источниками примеров послужили произведения русских и итальянских авторов, а также публицистические тексты, размещенные в национальных корпусах (Национальный корпус русского языка. URL: http://www.ruscorpora.ru/; Национальный корпус итальянского языка. URL: http:// www.corpora.unito.it).

\section{СПИСОК ЛИТЕРАТУРЫ}

1. Арутюнова, Н. Д. «Полагать» и «видеть» (к проблеме смешанных пропозициональных установок) / Н. Д. Арутюнова // Логический анализ языка. Проблемы интенсиональных и прагматических контекстов. - М. : Наука, 1989. - С. 7-30.

2. Баранов, А. И. Иллокутивное вынуждение в структуре диалога / А. И. Баранов, Г. Е. Крейдлин // Вопросы языкознания. - 1992. - № 2. - С. 84-99.

3. Баранов, А. Н. Путеводитель по дискурсивным словам русского языка / А. Н. Баранов, В. А. Плунгян, Е. В. Рахилина. - М. : Помовский и партнеры, 1993. - 207 с.

4. Гусев, В. Ю. Типология императива/ В. Ю. Гусев. - М. : Языки славянской культуры, 2013. - 336 с.

5. Падучева, Е. В. Дискурсивные слова и категории: режимы интерпретации / Е. В. Падучева // Исследования по теории грамматики. Выпуск 4 : Грамматические категории в дискурсе / отв. ред. В. А. Плунгян. - М. : Гнозис, 2008. - С. 56-86.

6. Формановская, Н. И. Речевое общение: коммуникативно-прагматический подход / Н. И. Формановская. - М. : Русский язык, 2002. -216 с.

7. Формановская, Н. И. Речевой этикет в русском общении. Теория и практика / Н. И. Формановская. - М. : ВК, 2009. - 334 с.

8. Формановская, Н. И. Речевой этикет. Русско-итальянские соответствия / Н. И. Формановская, Г. А. Красова. - М. : Высшая школа, 1992. - 143 с.

9. Формановская, Н. И. Русский речевой этикет: лингвистический и методический аспекты / Н. И. Формановская. - М. : Русский язык, 1987. - 158 с.

10. Храковский, В. С. Семантика и типология императива. Русский императив / В. С. Храковский, А. П. Володин. - М. : Едиториал УРСС, 2002. $272 \mathrm{c}$.

11. Ширяев, Е. Н. Глаголы речи, восприятия и мысли в роли разговорных модальных средств / Е. Н. Ширяев // Сокровенные смыслы: Слово. Текст. Культура : сб. ст. в честь Н. Д. Арутюновой / отв. ред. Ю. Д. Апресян. - М. : Языки славянской культуры, 2004. - С. 459-466.

12. Aijmer, K. Pragmatic markers / K. Aijmer // Handbook of Pragmatics Online. - 2009. - Electronic 
text data. - Mode of access: https://www.benjamins. com/online/hop (date of access: 03.01.2016). - Title from screen.

13. Bazzanella, C. I segnali discorsivi / C. Bazzanella // Grande grammatica italiana di consultazione. Vol. 3 : Tipi di frase, deissi, formazione delle parole / a cura di L. Renzi, G. Salvi, A. Cardinaletti (eds.). - Bologna : Il Mulino, 1988-1995. - P. 225-257.

14. Bertucelli Papi, M. Linguaggio della cortesia / M. Bertucelli Papi // Treccani, Enciclopedia dell'italiano. - 2010. - Electronic text data. - Mode of access: http://www.treccani.it/enciclopedia/ linguaggio-della-cortesia_\%28Enciclopediadell $\% 27$ Italiano\%29/. - Title from screen.

15. Erman, B. Pragmatic expressions in English: A study of 'you know', 'you see' and 'I mean' in faceto-face conversation / B. Erman. - Stockholm : Almqvist \& Wiksell, 1987. - 238 p.

16. Fraser, B. Pragmatic markers / B. Fraser // Pragmatics. - 1996. - № 6 (2). - P. 167-190.

17. Ghezzi, C. Guarda, secondo me stai sbagliando! Marcatori interazionali da verbi di percezione in italiano contemporaneo / C. Ghezzi // Progetto PRIN 2008 Mutamento e contatto tra varieta nella diacronia linguistica del Mediterraneo. Electronic text data. - Mode of access: http://www. mediling.eu/allegati/PRIN_t_risorse/4/FILE_ Documento_Ghezzi_Chiara_marcatori_interazionali da_verbi_di_percezione.pdf (date of access: 20.07.2016). - Title from screen.

18. Jucker, A. H. And people just you know like 'wow': Discourse markers as negotiating strategies / A. H. Jucker, S. W. Smith // Discourse Markers / A. H. Jucker, Y. Ziv (eds.). - Amsterdam : John Benjamins Publishing Company, 1998. - P. 171-201.

19. Lenk, U. Discourse Markers / U. Lenk // Handbook of Pragmatics. - Amsterdam : John Benjamins Publishing Company, 2005. - P. 1-17. Electronic text data. - Mode of access: https://www. benjamins.com/online/hop (date of access: 03.01.2016).Title from screen.

20. Manili, P. Per un'indagine su vedi, senti, guarda (e forme collegate) / P. Manili. - Perugia : Edizioni dell'Universita per Stranieri, 1983. - 86 p.

21. Östmann, J.-O. Pragmatic particles twenty years after / J.-O. Östmann // Organization in discourse / B. Wärvik, S.-K. Tanskanen, R. Hiltunen (eds.). Istanbul : University of Turku, 1995. - P. 95-108.

22. Schiffrin, D. Discourse Markers / D. Schiffrin. Cambridge: CambridgeUniversity Press, 1987.-Electronic text data. - Mode of access: http://dx.doi.org/10.1017/ CBO9780511611841 (date of access: 03.01.2016). - Title from screen.

23. Serianni, L. Grammatica italiana. Italiano comune e lingua letteraria. / L. Serianni. - Torino : UTET Universita, 2006. $-750 \mathrm{p}$.

\section{REFERENCES}

1. Arutyunova N.D. «Polagat» i «videt» (k probleme smeshannykh propozitsionalnykh ustanovok) [To "Suppose" and to "See" (on the Issue of Mixed Propositional Aims)]. Logicheskiy analiz yazyka. Problemy intensionalnykh i pragmaticheskikh kontekstov [Logical Analysis of Language. The Problems of Intentional and Pragmatic Contexts]. Moscow, Nauka Publ., 1989, pp. 7-30.

2. Baranov A.I., Kreydlin G.E. Illokutivnoe vynuzhdenie v strukture dialoga [Illocutionary Coercion in the Dialogue Structure]. Voprosy yazykoznaniya, 1992, no. 2, pp. 84-99.

3. Baranov A.N., Plungyan V.A., Rakhilina E.V. Putevoditel po diskursivnym slovam russkogo yazyka [A Guide to Discourse Words of the Russian Language]. Moscow, Pomovskiy i partnery Publ., 1993. $207 \mathrm{p}$.

4. Gusev V.Yu. Tipologiya imperativa [The Typology of the Imperative]. Moscow, Yazyki slavyanskoy kultury Publ., 2013.336 p.

5. Paducheva E.V. Diskursivnye slova i kategorii: rezhimy interpretatsii [Discourse Words and Categories: Interpretation Modes]. Plungyan V.A., ed. Issledovaniya po teorii grammatiki. Vyp. 4: Grammaticheskie kategorii v diskurse [Studies on the Theory of Grammar. Iss. 4: Grammar Categories in Discourse]. Moscow, Gnozis Publ. 2008, pp. 56-86.

6. Formanovskaya N.I. Rechevoe obshchenie: kommunikativno-pragmaticheskiy podkhod [Speech Communication: Communicative-Pragmatic Approach]. Moscow, Russkiy yazyk Publ., 2002. 216 p.

7. Formanovskaya N.I. Rechevoy etiket $v$ russkom obshchenii. Teoriya i praktika [Speech Etiquette in Russian Communication. Theory and Practice]. Moscow, VK Publ., 2009. 334 p.

8. Formanovskaya N.I. Krasova G.A. Rechevoy etiket. Russko-italyanskie sootvetstviya [Speech Etiquette. A Handbook of Russian-Italian Equivalences]. Moscow, Vysshaya shkola Publ., 1992. 143 p.

9. Formanovskaya N.I. Russkiy rechevoy etiket: lingvisticheskiy $i$ metodicheskiy aspekty [Russian Speech Etiquette: Linguistic and Methodical Aspects]. Moscow, Russkiy yazyk Publ., 1987. 158 p.

10. Khrakovskiy V.S., Volodin A.P. Semantika $i$ tipologiya imperativa. Russkiy imperativ [Semantics and Typology of Imperative. Russian Imperative.]. Moscow, Editorial URSS Publ., 2002. 272 p.

11. Shiryaev E.N. Glagoly rechi, vospriyatiya i mysli v roli razgovornykh modalnykh sredstv [Verbs of Speech, Perception and Thought as Talking Modal Agents]. Apresyan Yu.D., ed. Sokrovennye smysly: Slovo. Tekst. Kultura: Sbornik statey $v$ chest N.D. Arutyunovoy [Innermost Meanings: Word. Text. Culture. Collection in Honour ofN.D. Arutyunova]. 
Moscow, Yazyki slavyanskoy kultury Publ., 2004, pp. 459-466.

12. Aijmer K. Pragmatic markers. Handbook of Pragmatics Online, 2009. Available at: https:// www.benjamins.com/online/hop. (accessed January 3, 2016).

13. Bazzanella C. I segnali discorsivi [The Discourse Markers]. Renzi L., Salvi G., Cardinaletti A., eds. Grande grammatica italiana di consultazione. Vol. 3: Tipi di frase, deissi, formazione delle parole [Great Italian Grammar Consultation. Vol. 3: Sentence Types, Deixis, Word Formation]. Bologna, Il Mulino, 1988-1995, pp. 225-257.

14. Bertucelli Papi M. Linguaggio della cortesia [Language of the Courtesy]. Treccani, Enciclopedia dellitaliano, 2010. Available at: http://www.treccani.it/ enciclopedia/linguaggio-della-cortesia_\%28 Enciclopedia-dell\%27Italiano\%29/.

15. Erman B. Pragmatic expressions in English: A study of 'you know', 'you see' and 'I mean' in faceto-face conversation. Stockholm, Almqvist \& Wiksell, $1987.238 \mathrm{p}$.

16. Fraser B. Pragmatic markers. Pragmatics, 1996, no. 6 (2), pp. 167-190.

17. Ghezzi C. Guarda, secondo me stai sbagliando! Marcatori interazionali da verbi di percezione in italiano contemporaneo [Look, I think you're wrong! Interactional Markers of Verbs of Perception in Contemporary Italian]. Progetto PRIN 2008 Mutamento e contatto tra varieta nella diacronia linguistica del Mediterraneo [Project PRIN 2008
Change and Contact between Variedness in the Linguistic Diachrony of the Mediterranean Sea]. Available at: http://www.mediling.eu/allegati/ PRIN_t_risorse/4/FILE_Documento_Ghezzi_Chiara marcatori_interazionali_da_verbi_di_percezione.pdf. (accessed July 30, 2016).

18. Jucker A., Smith S.W. And people just you know like 'wow': Discourse markers as negotiating strategies. Jucker A.H., Ziv Y., eds. Discourse Markers, Amsterdam, John Benjamins Publishing Company, 1998, pp. 171-201.

19. Lenk U. Discourse Markers. Handbook of Pragmatics, Amsterdam, John Benjamins Publishing Company, 2005, pp. 1-17. Available at: https:// www.benjamins.com/online/hop. (accessed January 03, 2016).

20. Manili P. Per un'indagine su vedi, senti, guarda (e forme collegate) [For an Inquiry on See, Hear, Watch (and Associated Forms)]. Perugia, Edizioni dell'Universita per Stranieri, 1983. 86 p.

21. Östmann J.-O. Pragmatic particles twenty years after. Organization in discourse. Wärvik B., Tanskanen S-K., Hiltunen R., eds. Istanbul, University of Turku, 1995, pp. 95-108.

22. Schiffrin D. Discourse Markers. Cambridge, Cambridge University Press, 1987. Available at: http:/ /dx.doi.org/10.1017/CBO9780511611841. (accessed January 03, 2016).

23. Serianni L. Grammatica italiana. Italiano comune e lingua letteraria [Italian Grammar. Common Italian and Literary Language]. Torino, UTET Universita, 2006. $750 \mathrm{p}$.

\section{Information About the Author}

Natalya K. Guseva, Teacher, Department of Russian Language, Department of Foreign Languages and Literature, G. D’Annunzio University, Pindaro Blvd., 42, 65120 Pescara, Italy, nkonstguseva@gmail.com.

\section{Информация об авторе}

Наталья Константиновна Гусева, преподаватель кафедры русского языка, департамент иностранных языков и литературы, Университет им. Габриэля Д’Аннунцио, бульвар Пиндаро, 42, 65120 г. Пескара, Италия, nkonstguseva@gmail.com. 